j. port. sci. res.
ISSN: $2616-7441$ (Online)
ISSN: 2616-6232 (Print)
ISSN: 2616-7220 (USB)

\title{
Association of TNFRII polymorphisms and IL-37 in rheumatoid arthritis Iraqi patients
}

\author{
W. J. Mohammad ${ }^{1}$, N. A. Ibrahim ${ }^{2}$, S. F. Obed ${ }^{* 3}$, Sh. J. Mohammed ${ }^{4}$ \\ ${ }^{1,2}$ Department of Basic Sciences, College of Nursing, Baghdad University, Baghdad, Iraq. \\ ${ }^{3}$ College of Dentistry, Uruk University. Baghdad, Iraq. \\ ${ }^{4}$ College of Health and Medical Technology, Central Technical University. Bagdad, Iraq.
}

\section{shahad.alkhafaji@uruk.edu.iq}

\begin{abstract}
Fifty RA patients and 50 healthy individuals have been participated in this study. 196 M/R polymorphism of TNFRII gene determined by PCR-RFLP, IL-37 level was measured by ELISA technique, also RF, ACCP, CRP measured by ELISA technique. Our study shows an increase in IL-37 levels in patients was suffered from rheumatoid arthritis relative to control group. $(\mathrm{M}=101.31+10.41)$ That shows major differences between patients and controls $(\mathrm{p}<0.01)$ and increasing level of IL-37 correlate significantly with increasing level of CRP $(\mathrm{p}<0.05)$. The frequencies of TNFRII gene polymorphism were significantly correlate with the IL-37 level $(\mathrm{p}<0.01)$ in RA patients compared with control group. In conclusion, IL-37 increased in RA patients associated with disease development, also significantly associated with TNFRII polymorphism.
\end{abstract}

Crossref

10.36371/port.2021.1.7

Keywords: Interleukin- (IL-37); PCR-RFLP, IL-37; TNFRII; ACCP, CRP.

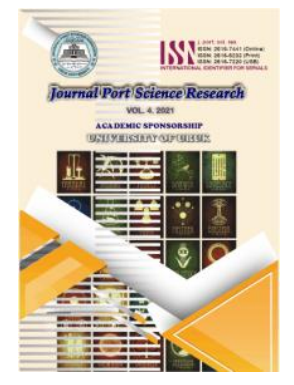

\section{INTRODUCTION}

Rheumatoid arthritis (RA) is a chronic inflammatory condition identified by chronic persistent inflammatory cells. At first the patient complains about pain and inflammatory events restricting the lifestyle within the synovium are frequent and damaging [1]. These immune changes result in many of the clinical effects and adverse articular changes that characterize such disorders. Most, if not all, of the bone damage in RA. Results from inflammatory osteolysis, a process by which osteoclasts resorb bone [2]. Inflammatory cytokines, especially TNF $-\alpha$, have been shown to stimulate differentiation of macrophage progenitors into activated osteoclasts. In rheumatoid synovium, the main origins of TNF are the cells of the macrophage - monocyte family.[3] .

TNF $-\alpha$ mediates its biological effects through the TNF RI and TNF RII which are type I transmembrane proteins consisting of an extracellular $\mathrm{N}$ terminus and an intracellular $\mathrm{C}$ terminus. The extracellular forms of these receptors (also termed soluble receptor), which circulate in healthy humans TNF RII tends to bind the cell - surface TNF $-\alpha$ and can also serve as a transport molecule to transmit TNF $-\alpha$ to TNF RI. TNF RII has similar affinity for TNF $-\alpha$ to the type I receptor, but the binding of ligand is much longer, TNF receptors are an important way to reduce TNF - induced inflammation.[4]

By $2000, \mathrm{IL}-37$ was identified as a constituent of the novel ILe -1 cluster genes, its Nevertheless, its functional and
Biological Impacts were undetermined [5]. Various research groups concluded through studies on the biological function of IL-18 BP that more dose levels of this cytokine improved plaque psoriasis and RA, in vivo and vitro [6,7]. It has been suggested that IL $-18 \mathrm{R}$ can bind, in addition to ILBP, another orphan ligand, thus also disabling a pro-inflammatory immune response.

Further research revealed that there was the orphan ligand, and it was IL-37. It has been verified however that IL-37 can bind both IL-18R and IL-BP. There will be five alternative spleen-based variants of this cytokine including (IL 37a,1L37b, IL37c, IL37d, IL37, IL37e) of them, IL - 37b which is the most stable isoform and contributes to the best studied IL isoform - 37 expressed in multiple tissues and organs such as heart, brain, lung, spleen, prostate, pancreas, stomach, kidney, and liver [9]. In addition, tumors showed higher rates of IL-37 aspersed in variants, expressed in both colon carcinomas stroma and ductal mammary melanoma and carcinoma cells, lung carcinoma but not prostate cancer.[9]

According to recent research, IL-37, play a significant role in regulating the immune system. Unlike IL-1 $\alpha$ or IL-33e, It is deemed to be an intercellular nuclear factor regulating gene expression [10,11]. Nolde et al., 2010 showed IL -4 down regulated IL expression - 37, inhibited DC activation and differentiation, and significantly suppressed innate immunity.[12,13] . 
There is confirmation that IL-37 anti-inflammatory activities can be conducted by inhibiting the signaling pathway of decapentaplegic homdog 3 (smad 3$)$. Smad 3 is a TGF- $\beta$ function modulator stated to be related to impaired local inflammatory response [14], cytotoxicity inhibition [15], and the suppression of TGF macrophages activation and DCs $-\beta$ mediated down multiple cytokine regulation [16,17]. All these - the above results suggest that IL -37 is a major suppressant of systemic and local inflammation. This research was done to determine whether there is any improvement in developmental stage of IL-37 and interaction of IL-37 and TNFRII gene polymorphism.

This work was done to determine whether the level of IL-37 and the relationship of IL-37 and TNFRII gene polymorphism in the development and severity of RA in Iraqi patients is increasing.

\section{PATIENTS AND METHODS}

The research involves 50 Iraqi RA patients who were diagnosed according to American rheumatology college guidelines. Patients included in the analysis were subjected to routine biochemical blood tests, they evaluation by physical examination with a emphasis on joint involvement and laboratory features such as RF rheumatoid factor and ACCP anti-citrullinated peptide antibody. Disease activity was determined based on the number of swollen joints, ESR, questionnaire for the health evaluation and C-reactive protein CRP. Fifty stable Iraqis had been employed as a control group. They by no means had any symptoms or signs at any site of RA, different arthritis, or joint disorder based totally on their clinical history and examination (pain, swelling, tenderness, or movement restriction).

Extraction of DNA: DNAwas isolation from EDTA wholeblood sample the use of Relia-prep in accordance to the protocol (Promega, USA). Amplification of TNFRII polymorphism: the studied companies were genotyped for TNFRII exon 6 polymorphisms by PCR-RFLP. The PCR response was once conducted in a $25 \mathrm{ul}$ response that covered 12.5ul of Green Master Mix, 1ul of 10pmol / ul of each primary, 5ul of DNA template, and the volume was once done to $25 \mathrm{ul}$ using nuclease-free water. Master Mix is made up of polymerase dNTPs, Mgcl2, Taq.

For TNFRII polymorphism, the region surrounding the polymorphisms had amplified with following forward primer 5 ACTCTCCTATCCTGCCTGCT 3 and reverse primer 5 TTCTGGAGTTGGCTGCGTGT 3. PCR had performed at initial step at $95{ }^{\circ} \mathrm{C}$ for $4 \mathrm{~min}$, followed by denaturation step at $95 \mathrm{c}^{\circ}$ for $30 \mathrm{sec}$, annealing step at $58^{\circ} \mathrm{C}$ for $30 \mathrm{sec}$, extension step at $72^{\circ} \mathrm{C}$ for $1 \mathrm{~min}$ and repeat step $2-4$ for 34 cycles. After that extension at $72{ }^{\circ} \mathrm{C}$ for $10 \mathrm{~min}$. holding at $4^{\circ} \mathrm{C}$. Serum analysis: sera were separated immediately and sored at -20c. CRP, ACCP, RF, and IL-37 are assayed by enzymelinked immunosorbent assay (ELISA).

\section{RESULTS}

Table one explained the comparison between patients and control group in the level of IL-37 and inflammation markers which showed significant difference between patients and control through increasing the level of IL-37 in patients of rheumatoid arthritis $(\mathrm{p}<0.01)$.

Table (1): Comparison of patients and control in IL-37 level inflammation markers.

\begin{tabular}{|c|c|c|c|c|c|c|}
\hline \multirow{2}{*}{ Group } & \multirow{6}{|c|}{ No. } & \multicolumn{6}{|c|}{ Mean \pm SE } \\
\cline { 3 - 7 } & & $\begin{array}{c}\text { IL-37 } \\
\mathrm{ng} / \mathrm{ml})\end{array}$ & ESRmm/hr. & CRPmg/L & RFU/ml & ACPAU/ml \\
\hline Patients & 50 & $\begin{array}{c}101.31 \\
\pm 10.41\end{array}$ & $\begin{array}{c}52.96 \pm \\
3.68\end{array}$ & $\begin{array}{c}38.39 \pm \\
4.31\end{array}$ & $\begin{array}{c}168.87 \pm \\
31.62\end{array}$ & $\begin{array}{c}114.85 \pm \\
21.06\end{array}$ \\
\hline Control & 50 & $\begin{array}{c}43.90 \pm \\
0.91\end{array}$ & $\begin{array}{c}10.44 \pm \\
0.74\end{array}$ & $\begin{array}{c}16.49 \pm \\
2.51\end{array}$ & $4.96 \pm 0.71$ & $1.71 \pm 0.13$ \\
\hline $\begin{array}{c}\text { LSD } \\
\text { value }\end{array}$ & --- & $20.550 * *$ & $7.459 * *$ & $9.918 * *$ & $62.766 * *$ & $41.801 * *$ \\
\hline \multicolumn{7}{|c|}{$* *(\mathrm{P}<0.01)}$. \\
\hline
\end{tabular}

Table tow appeared the clinical signs relation with IL37 in the study group of patients.

Table (2) The clinical signs relation with IL37 in the study group.

\begin{tabular}{|c|c|c|c|}
\hline Sex & No. & Mean \pm SE of IL-37 & LSD value \\
\hline Male & 6 & $147.65 \pm 28.00$ & $31.668 *$ \\
\hline Female & 44 & $97.08 \pm 10.46$ & \\
\hline \multicolumn{4}{|c|}{ Age groups (year) } \\
\hline Less than 30 & 7 & $97.11 \pm 27.81$ & \multirow[t]{3}{*}{$26.052 *$} \\
\hline $30-50$ & 31 & $111.21 \pm 15.05$ & \\
\hline More than 50 & 12 & $77.36 \pm 6.98$ & \\
\hline \multicolumn{4}{|c|}{ Duration of disease (year) } \\
\hline Less than 5 & 26 & $92.35 \pm 22.69$ & \multirow[t]{3}{*}{$31.074 \mathrm{NS}$} \\
\hline $5-10$ & 16 & $97.61 \pm 17.92$ & \\
\hline More than 10 & 8 & $86.28 \pm 20.55$ & \\
\hline \multicolumn{4}{|c|}{ No. of painful and swollen (joints) } \\
\hline Less than 5 & 22 & $86.42 \pm 15.78$ & \multirow[t]{3}{*}{$29.812 \mathrm{NS}$} \\
\hline $5-10$ & 20 & $103.66 \pm 23.85$ & \\
\hline More than 10 & 8 & $92.93 \pm 20.07$ & \\
\hline \multicolumn{4}{|c|}{ Morning stiffness } \\
\hline Yes & 33 & $101.48 \pm 21.95$ & \multirow[t]{2}{*}{$22.961 \mathrm{NS}$} \\
\hline No & 17 & $92.39 \pm 16.54$ & \\
\hline \multicolumn{4}{|c|}{$*(\mathrm{P}<0.05 \mathrm{e}), \mathrm{NS}:$ Non-significant. } \\
\hline
\end{tabular}

Table (3): confirmed a coefficient of correlation between the parameters of the sample and IL-37 showing significant variations ( $\mathrm{P}<0.05)$ between IL-37 and CRP, displaying even non-significant variations $(\mathrm{P}<0.05)$ between $\mathrm{IL}-37$ with all parameters (ACPA, ESR, RF).

Table (3). Correlation coefficient between study parameters. \begin{tabular}{|l|l|l|}
\hline Correlated Parameters & Correlation coefficient $(\mathrm{r})$ & Level of sig. \\
\hline
\end{tabular}

\begin{tabular}{|c|c|c|}
\hline ACPA \& IL-37 & -0.07 & NS \\
\hline ESR \& IL-37 & 0.02 & NS \\
\hline RF \& IL-37 & -0.09 & NS \\
\hline CRP \& IL-37 & 0.19 & $*$ \\
\hline
\end{tabular}

Table (4): showed the relationship between genotype of EXON 6 TNFRII gene and IL-37 of patients with RA which show significant relationship $(\mathrm{P}<0.01)$ with $(\mathrm{MM}, \mathrm{MR}, \mathrm{RR})$ EXON 6 TNFRII and IL-37 $(\mathrm{P}<0.01)$. While table 24 showed 
non-significant relationship ( $\mathrm{P}>0.01)$ between genotypes of EXON 6 TNFRII and IL-37 in control group.

Table (4). Relationship between genotype of Exon6 TNFII gene and IL-37 of patients and control

\begin{tabular}{|c|c|c|c|}
\hline $\begin{array}{c}\text { Genotype Exon6 TNFII of } \\
\text { patients }\end{array}$ & No. & $\begin{array}{c}\text { Mean } \pm \text { SE of IL- } \\
37\end{array}$ & $\begin{array}{c}\text { LSD } \\
\text { value }\end{array}$ \\
\cline { 1 - 3 } MM & 30 & $99.08 \pm 12.59$ & \multirow{3}{*}{$37.612 * *$} \\
MR & 16 & $121.32 \pm 22.32$ & \\
\hline RR & 4 & $67.55 \pm 9.69$ & \\
\cline { 1 - 3 } Genotype Exon6 TNFII of control \\
\cline { 1 - 3 } MM & 26 & $44.55 \pm 1.19$ & \multirow{2}{*}{} \\
\cline { 1 - 3 } MR & 21 & $42.90 \pm 1.40$ & \\
\cline { 1 - 3 } RR & 3 & $45.25 \pm 6.44$ & \\
\hline
\end{tabular}

\section{DISCUSSION}

Though Interleukin-37 (IL-37) is strongly correlated with many inflammatory diseases, its function in RA. Pathogenesis is as yet unclear. IL-37 is a recently proven natural, anti-inflammatory cytokine that suppresses immune and inflammatory reactions. This has properties both intraand extracellular [18]. New study showing markedly elevated serum level of IL-37 in patients with RA relative to the typical control group level. These findings are consistent with the results obtained from a recent study conducted in northeast China between 2011-2012 including an elevation of IL-37 [19] in RA patients.

Also, our results regarding serum level of IL-37 are consistent with results of recent study in Shanghai described China plasma showing Increased IL-37 level in active RA patients [20]. Many research lately, e.g., Yang et al. 2015 concluded that in RA patients substantially higher serum levels of IL-37 were established in comparison with stable controls (HCs) $(\mathrm{p}<0.001)$. Xia et al. 2015 also reported that RA serum patients, the level of IL-37 were significantly increased compared with those of osteoarthritis (OA) and healthy controls (HC) particularly in those with positive RF \& positive CCP.

The elevated level of IL-37 in RA can be clarified as the underlying mechanism for relieving joint inflammation and severity of the disease but is still too small to neutralize the harmful effects of progressive RA pro-inflammatory cytokines [21].

The anti-inflammatory cytokines inadequate antagonism to pro-inflammatory cytokines may be explained by using the unregulated inflammation in RA \&amp; associated with sickness exercise instead of sickness remission. (Ting et al, 2015) findings point out that IL-37 may be a feasible biomarker of lively RA \&amp; may additionally play an essential role in sickness pathogenesis.

Another research by Xia et al, (2015) found that the serum level of IL-37 in patients with RA was significantly higher than in osteoarthritis patients (OA) and healthy controls (HC), and especially positive RF factor patients and anti- (CCP) levels [22].
After anti-TNF- $\alpha$ the level of IL-37 in serum patients decreased dramatically, plus the level of IL-37 significantly down-regulated production of IL-6, IL-17 and TNF- $\alpha$ by RA patient PBMC. This small print may additionally give an explanation for that IL-37 is the most considerable antiinflammatory cytokine in the regulation of RA pathogenesis by way of suppressing the development of inflammatory cytokine. There is still no sturdy proof about IL-37's antiinflammatory function. There are presently two theories; either IL-37 active in extracellular space can inhibit the function of pro-inflammatory cytokines or their receptors [23], this has been proven by means of immunohistochemical staining of synovial coating in lively RA showing greater stages of IL-37 in contrast to HCs.[24]

The IL- 37 protein had additionally been located in plasma patients with extreme systemic Lupus Erythematous, and in Crohn's disease. It was once located to be protective against septic shock, DSS-induced colon cancer and ischemia / reperfusion (I / R)-induced experimental form of hepatitis [25]. IL-37's results are attributed to its capability to decrease the development of pro-inflammatory cytokine and chemokine [26]. While the affiliation between disease pastime and IL-37 in sufferers with RA had now not but been studied, the findings of this study confirmed that IL-37's serum level used to be positively associated with CRP. In 2014, Zhao et al. confirmed that IL-37 plasma stage also had a positive association with ailment activity (CRP).

Interleukin-37 (IL-37) expends wide-ranging inhibitory effects on the innate inflammatory and immune response. This is the reality that the present research considers the first research to investigate the relationship between the level of IL-37 and TNFRII gene genotypes in patients with rheumatoid arthritis compared to healthy controls in the Iraqi region, suggesting a substantial correlation $(\mathrm{p}<0.01)$ between the level of IL-37 genotypes and TNFRII genotypes. Research checks the stage of IL-37 in serum patients with RA had been extensively greater in contrast with these of healthful controls (HC). In the latest work in contrast RA Synovial fluid and serum specimens; the stages of SF IL-37 have been an awful lot increased than these in the serum. The serum IL-37 degrees diminished notably after anti-TNF- $\alpha$ therapy. In contrast, human recombinant IL-37 drastically down-regulated development of TNF- $\alpha$, IL-17, and IL- 6 by RA patient PBMCs. TNF- $\alpha$ is a crucial pro-inflammatory cytokine in RA pathogenesis which is thought to induce molecular adhesion, proteinase gene expression and play an important role in the production of joint destruction and synoviocyte proliferation [27] In a range of ailments IL-37 has been pronounced to play an anti-inflammatory position [28]. Many cytokines, both anti- and pro-inflammatory, have been identified in diseases brought about by means of inflammation and the stability between these opposing cytokine things to do has been shown to manipulate the severity of the disease. RA is carefully associated with growing the expression of TNF- $\alpha$. Consequently, inhibition 
of TNF- $\alpha$ expression is a promising strategy for the improvement of new anti-therapies. What is anti-function IL37 is still unclear. There are two hypotheses: either IL-37 is secreted into the extracellular house to inhibit the feature of pro-inflammatory cytokines or their receptors, or IL-37 translocates to the nucleus where it is related with $\operatorname{Smad} 3$ to block the transcription of pro-inflammatory cytokine genes .[29]

By comparison, pro-inflammatory cytokines, IFN-c, IL-1b, IL-18 and TNF-a might also extend IL-37 synthesis in human peripheral mononuclear blood cell affiliation between TNFRII genotypes and IL-37 ranges point out that IL-37 may additionally be activated by means of pro-inflammatory cytokines or other unknown factors in the acute RA cycle. The serum stage of IL-37 in RA sufferers has been proven to be strongly related to TNFRII genotypes in the modern study. In line with the results, an before study said that TNF- $\alpha$ may want to extend the synthesis of IL-37 in PBMCs successfully by the use of immunoblot evaluation of cellphone lysate [31].
The study consequences also correlated with the idea that the manufacturing of IL-37 used to be by and large regulated by proinflammatory cytokines and RA restoration tactics throughout the acute period. This IL-37 counseled ought to be part of a feedback loop for infection control. Nevertheless, this mechanism does no longer feature correctly to control inflammation all through successful RA both due to the fact the expression of IL-37 is ineffective, or due to the fact unknown factors have neutralized IL-37 effects. Such latest outcomes can also provide new insights into appreciation the pathogenesis of RA. Further research supporting a thorough understanding of the position of IL-37 in the manipulate of RA pathogenesis.[31]

Conclusion: The new work can also furnish new insights into perception the pathogenesis of RA. More lookup supporting a thorough understanding of the position of IL-37 in controlling pathogenesis of RA. Of this, the findings of the find out about cautioned future studies to decide the role and mechanisms of IL-37 in controlling the pathogenic RA cycle.

\section{REFERENCES}

[1] Brennan, F. M., \& McInnes, I. B. (2008, November 3). Evidence that cytokines play a role in rheumatoid arthritis. Journal of Clinical Investigation. https://doi.org/10.1172/JCI36389

[2] Choy, E. (2012). Understanding the dynamics: Pathways involved in the pathogenesis of rheumatoid arthritis. Rheumatology (United Kingdom), 51(SUPPL.5). https://doi.org/10.1093/rheumatology/kes113

[3] Barton, A., John, S., Ollier, W. E. R., Silman, A., \& Worthington, J. (2001). Association between rheumatoid arthritis and polymorphism of tumor necrosis factor receptor II, but not tumor necrosis factor receptor I, in Caucasians. Arthritis and Rheumatism, 44(1), 61-65. https://doi.org/10.1002/1529-0131(200101)44:1<61::AID-ANR9>3.0.CO;2-Q

[4] Bayley, J. P., Ottenhoff, T. H. M., \& Verweij, C. L. (2004, August). Is there a future for TNF promoter polymorphisms? Genes and Immunity. https://doi.org/10.1038/sj.gene.6364055

[5] Sharma, S., Kulk, N., Nold, M. F., Gräf, R., Kim, S.-H., Reinhardt, D., .. Bufler, P. (2008). The IL-1 Family Member 7b Translocates to the Nucleus and Down-Regulates Proinflammatory Cytokines. The Journal of Immunology, 180(8), 54775482. https://doi.org/10.4049/jimmunol.180.8.5477

[6] Banda, N. K., Vondracek, A., Kraus, D., Dinarello, C. A., Kim, S.-H., Bendele, A., ... Arend, W. P. (2003). Mechanisms of Inhibition of Collagen-Induced Arthritis by Murine IL-18 Binding Protein. The Journal of Immunology, 170(4), 2100-2105. https://doi.org/10.4049/jimmunol.170.4.2100

[7] Tak, P. P., Bacchi, M., Bertolino, M., \& Desson, A. (2006). Pharmacokinetics of IL-18 binding protein in healthy volunteers and subjects with rheumatoid arthritis or plaque psoriasis. European Journal of Drug Metabolism and Pharmacokinetics, 31(2), 109-116. https://doi.org/10.1007/BF03191127

[8] Bufler, P., Azam, T., Gamboni-Robertson, F., Reznikov, L. L., Kumar, S., Dinarello, C. A., \& Kim, S. H. (2002). A complex of the IL-1 homologue IL-1F7b and IL-18-binding protein reduces IL-18 activity. Proceedings of the National Academy of Sciences of the United States of America, 99(21), 13723-13728. https://doi.org/10.1073/pnas.212519099

[9] Kumar, S., Hanning, C. R., Brigham-Burke, M. R., Rieman, D. J., Lehr, R., Khandekar, S., Kirkpatrick, R. B., Scott, G. F., Lee, J. C., Lynch, F. J., Gao, W., Gambotto, A., \& Lotze, M. T. (2002). Interleukin-1F7B (IL-1H4/IL-1F7) is processed by caspase-1 and mature IL-1F7B binds to the IL-18 receptor but does not induce IFN-gamma production. Cytokine, 18(2), 6171. https://doi.org/10.1006/cyto.2002.0873 
[10] Sharma, S., Kulk, N., Nold, M. F., Gräf, R., Kim, S.-H., Reinhardt, D., ... Bufler, P. (2008). The IL-1 Family Member 7b Translocates to the Nucleus and Down-Regulates Proinflammatory Cytokines. The Journal of Immunology, 180(8), 54775482. https://doi.org/10.4049/jimmunol.180.8.5477

[11] Ross, R., Grimmel, J., Goedicke, S., Möbus, A. M., Bulau, A. M., Bufler, P., ... Martin, M. U. (2013). Analysis of nuclear localization of interleukin-1 family cytokines by flow cytometry. Journal of Immunological Methods, 387(1-2), 219-227. https://doi.org/10.1016/j.jim.2012.10.017

[12] Nold, M. F., Nold-Petry, C. A., Zepp, J. A., Palmer, B. E., Bufler, P., \& Dinarello, C. A. (2010). IL-37 is a fundamental inhibitor of innate immunity. Nature Immunology, 11(11), 1014-1022. https://doi.org/10.1038/ni.1944

[13] Imaeda, H., Takahashi, K., Fujimoto, T., Kasumi, E., Ban, H., Bamba, S., ... Andoh, A. (2013). Epithelial expression of interleukin-37b in inflammatory bowel disease. Clinical and Experimental Immunology, 172(3), 410-416. https://doi.org/10.1111/cei.12061

[14] Ashcroft, G. S., Yang, X., Glick, A. B., Weinstein, M., Letterio, J. J., Mizel, D. E., .. Roberts, A. B. (1999). Mice lacking Smad3 show accelerated wound healing and an impaired local inflammatory response. Nature Cell Biology, 1(5), 260-266. https://doi.org/10.1038/12971

[15] Al-Sarray, E. (2019). Organic compound that excels Barite and polymer in gamma ray's attenuation. International Journal of Energy and Water Resources, 3(3), 247-251. https://doi.org/10.1007/s42108-019-00034-8

[16] D’Angeac, A. D., Dornand, J., Emonds-Alt, X., Jullien, P., Garcia-Sanz, J. A., \& Erard, F. (1991). Transforming growth factor type beta 1 (TGF- $\beta 1$ ) down-regulates interleukin-2 production and up-regulates interleukin-2 receptor expression in a thymoma cell line. Journal of Cellular Physiology, 147(3), 460-469. https://doi.org/10.1002/jcp.1041470312

[17] Werner, F., Jain, M. K., Feinberg, M. W., Sibinga, N. E., Pellacani, A., Wiesel, P., Chin, M. T., Topper, J. N., Perrella, M. A., \& Lee, M. E. (2000). Transforming growth factor-beta 1 inhibition of macrophage activation is mediated via Smad3. The Journal of biological chemistry, 275(47), 36653-36658. https://doi.org/10.1074/jbc.M004536200

[18] Bulau, A. M., Nold, M. F., Li, S., Nold-Petry, C. A., Fink, M., Mansell, A., ... Bufler, P. (2014). Role of caspase-1 in nuclear translocation of IL-37, release of the cytokine, and IL-37 inhibition of innate immune responses. Proceedings of the National Academy of Sciences of the United States of America,111(7), 2650-2655. https://doi.org/10.1073/pnas.1324140111

[19] Zhao, P. W., Jiang, W. G., Wang, L., Jiang, Z. Y., Shan, Y. X., \& Jiang, Y. F. (2014). Plasma levels of IL-37 and correlation with TNF-a, IL-17A, and Disease activity during DMARD treatment of rheumatoid arthritis. PLoS ONE, 9(5). https://doi.org/10.1371/journal.pone.0095346

[20] Xia, T., Zheng, X. F., Qian, B. H., Fang, H., Wang, J. J., Zhang, L. L., ... Zhao, D. B. (2015). Plasma interleukin-37 is elevated in patients with rheumatoid arthritis: Its correlation with disease activity and Th1/Th2/Th17-related cytokines. Disease Markers, 2015. https://doi.org/10.1155/2015/795043

[21] Ebrahiem, S. A., Falih, E. H., Mahdi, H. A. M., \& Shaban, A. H. (2018). Indoor 222Rn measurement and hazards indices in houses of Al-Najaf province - Iraq. In AIP Conference Proceedings (Vol. 1968). American Institute of Physics Inc. https://doi.org/10.1063/1.5039190

[22] Xia, T., Zheng, X. F., Qian, B. H., Fang, H., Wang, J. J., Zhang, L. L., ... Zhao, D. B. (2015). Plasma interleukin-37 is elevated in patients with rheumatoid arthritis: Its correlation with disease activity and Th1/Th2/Th17-related cytokines. Disease Markers, 2015. https://doi.org/10.1155/2015/795043

[23] Xia, L., Shen, H., \& Lu, J. (2015). Elevated serum and synovial fluid levels of interleukin-37 in patients with rheumatoid arthritis: Attenuated the production of inflammatory cytokines. Cytokine, 76(2), 553-557. https://doi.org/10.1016/j.cyto.2015.06.005

[24] Bufler, P., Azam, T., Gamboni-Robertson, F., Reznikov, L. L., Kumar, S., Dinarello, C. A., \& Kim, S. H. (2002). A complex of the IL-1 homologue IL-1F7b and IL-18-binding protein reduces IL-18 activity. Proceedings of the National Academy of Sciences of the United States of America, 99(21), 13723-13728. https://doi.org/10.1073/pnas.212519099

[25] Nold, M. F., Nold-Petry, C. A., Zepp, J. A., Palmer, B. E., Bufler, P., \& Dinarello, C. A. (2010). IL-37 is a fundamental inhibitor of innate immunity. Nature Immunology, 11(11), 1014-1022. https://doi.org/10.1038/ni.1944 
[26] Boraschi, D., Lucchesi, D., Hainzl, S., Leitner, M., Maier, E., Mangelberger, D., ... Dinarello, C. A. (2011, September). IL-37: A new anti-inflammatory cytokine of the IL-1 family. European Cytokine Network. https://doi.org/10.1684/ecn.2011.0288

[27] Bulau, A. M., Fink, M., Maucksch, C., Kappler, R., Mayr, D., Wagner, K., \& Bufler, P. (2011). In vivo expression of interleukin-37 reduces local and systemic inflammation in concanavalin A-induced hepatitis. TheScientificWorldJournal, 11, 2480-2490. https://doi.org/10.1100/2011/968479

[28] Sakai, N., Van Sweringen, H. L., Belizaire, R. M., Quillin, R. C., Schuster, R., Blanchard, J., ... Lentsch, A. B. (2012). Interleukin-37 reduces liver inflammatory injury via effects on hepatocytes and non-parenchymal cells. Journal of Gastroenterology and Hepatology (Australia), 27(10), 1609-1616. https://doi.org/10.1111/j.1440-1746.2012.07187.x

[29] Chu, K., Zheng, H., Li, H., Zhang, Y., Zhang, X., Xu, W., \& Chen, L. (2013). Shuangtengbitong tincture treatment of collagen-induced arthritis via downregulation of the expression of IL-6, IL-8, TNF- $\alpha$ and NF- $\mathrm{kB}$. Experimental and Therapeutic Medicine, 5(2), 423-428. https://doi.org/10.3892/etm.2012.853

[30] PhD, M. A. M. D., PhD, S. B., PhD, R. C., MD, T. E., PhD, H. F. M. D., PhD, E. G., ... MD, C. A. A. (2011). Interleukins, from 1 to 37, and interferon- $\gamma$ : Receptors, functions, and roles in diseases. Journal of Allergy and Clinical Immunology, 127(3), 701-721.e70. Retrieved from http://dx.doi.org/10.1016/j.jaci.2010.11.050

[31]Tetè, S., Tripodi, D., Rosati, M., Conti, F., Maccauro, G., Saggini, A., ... Theoharides, T. C. (2012). IL-37 (IL-1F7) the newest anti-inflammatory cytokine which suppresses immune responses and inflammation. International Journal of Immunopathology and Pharmacology. Biolife s.a.s. https://doi.org/10.1177/039463201202500105 